\title{
Arylation Reactions: A Historical Perspective
}

\author{
Lutz Ackermann
}

\section{1}

\section{Structure and Bonding of Benzene}

Substituted arenes and heteroarenes are ubiquitous substructures of both naturally occurring and synthetic organic compounds which have activities that are relevant to a variety of research areas, ranging from biology to the materials sciences. Representative examples of historically important synthetic arenes include the analgesic aspirin, acetylsalicylic acid (1), or the first natural pigment to be duplicated synthetically in an industrial environment, alizarin (2) (Figure 1.1).

The specific activities displayed by arene-containing compounds are due largely to the remarkable relative stability and, thus, the unique chemical reactivity of arenes. As a result, their structure and bonding were one of the most fascinating problems facing chemists during the mid-nineteenth century. Interestingly, a cyclic planar structure was first described for benzene and its derivatives by Johann Josef Loschmidt in 1861 (Figure 1.2), a pioneer of nineteenth-century physics and chemistry [1].

Loschmidt proposed circular planar structures for 121 arenes, including those of benzene (3) and aniline (4) (Figure 1.3) [1, 2]. Whilst the chemical formulae for further important structural motifs, such as cyclopropanes, as well as multiple carbon-carbon bonds, were also proposed in this prescient report, it was largely ignored by the chemical community. Indeed, it was not until 1913 that Loschmidts' work was recognized by Richard Anschütz who, interestingly, was one of August Friedrich Kekulé von Stradonitz's students [3].

In 1865, August Friedrich Kekulé von Stradonitz (Figure 1.4) suggested a planar structure for benzene, in which carbon-carbon single and carbon-carbon double bonds alternated within a six-membered ring [4]. However, this proposal did not account for the observation of only one isomer of ortho-disubstituted benzenes. Therefore, Kekulé revised his model in 1872, postulating a rapid equilibrium between two structures (Scheme 1.1). This beautiful $D_{6 \mathrm{~h}}$-symmetrical structure of benzene was later confirmed by its X-ray crystal structure and its electrondiffraction data, which highlighted the equivalence of all six carbon-carbon bonds 
<smiles>CC(=O)Oc1ccccc1C(=O)O</smiles><smiles>O=C1c2ccccc2C(=O)c2c1ccc(O)c2O</smiles>

2

Figure 1.1 Selected historically relevant substituted arenes.

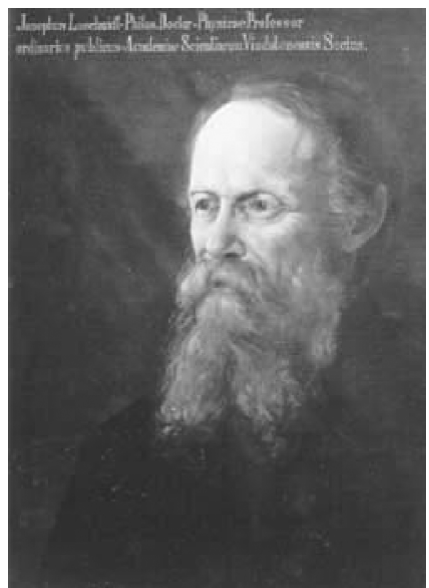

Figure 1.2 Johann Josef Loschmidt (15 March 1821-8 July 1895).

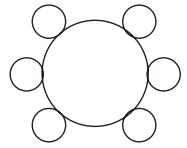

3

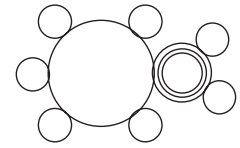

4

Figure 1.3 Loschmidt's molecular structural formulae for benzene (3) and aniline (4).

[5]. According to R. Robinson (1925), these experimentally obtained data are represented by the commonly used symbol 5 , in which delocalized $\pi$-electrons are represented by a circle within a hexagon (Scheme 1.1).

The term 'aromatic' was coined in 1855 by August Wilhelm von Hofmann (1818-1892), before the physical mechanism determining so-called aromaticity was unraveled. Originally, this definition was derived from a characteristic property, namely a sweet scent that was associated with some 'aromatic' compounds. Subsequently, it was shown that arenes are unsaturated compounds, but showed a chemical reactivity which differed from that of both alkenes or alkynes. This unique reactivity pattern of arenes was used at the end of the nineteenth century as the only criterion of aromaticity. At the start of the twentieth century, additional 


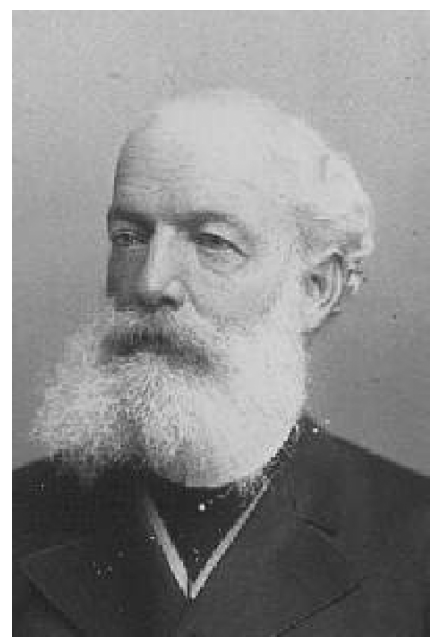

Figure 1.4 August Friedrich Kekulé von Stradonitz (7 September 1829-13 July 1896).

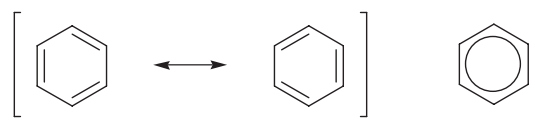

5

Scheme 1.1 Structural representations of $D_{6 h}$-symmetrical benzene.

criteria of aromaticity were elaborated, such as the relative stability of arenes with respect to the corresponding hypothetical cyclooligoenes [6]. Later, the development of quantum mechanics set the stage for the molecular orbital theory, the application of which enabled Hückel to devise his well-known $(4 n+2)$ rule as a criterion for aromaticity in 1931 [7, 8]. A definition of aromaticity based on carboncarbon bond lengths in arenes was also delineated during the twentieth century. While this model proved useful where accurate bond lengths were available, it was, unfortunately, found not to be generally applicable [9]. Hence, today one of the most reliable criteria of aromaticity is based on the magnetic properties of arenes. The anomalous chemical shifts of resonances in ${ }^{1} \mathrm{H}$ NMR spectra led to less satisfactory analyses for some compounds. In contrast, the diamagnetic susceptibility exaltation [6] or the nucleus-independent chemical shift (NICS) [10] were found often to be more reliable criteria of aromaticity [5, 11].

\section{2}

\section{Syntheses of Substituted (Hetero)Arenes, and the Contents of this Book}

Historically, the name 'benzene' derives from benzoin, which was known to European pharmacists and perfumers since the fifteenth century. Thus, pure benzene 
<smiles>[O-]c1ccccc1</smiles>

6

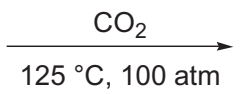

$125^{\circ} \mathrm{C}, 100 \mathrm{~atm}$

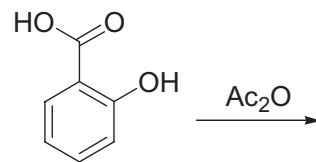

7<smiles>CC(=O)Oc1ccccc1C(=O)O</smiles>

1

Scheme 1.2 Industrial synthesis of acetylsalicylic acid (1) (ASA, aspirin, 1897).<smiles></smiles><smiles>O=C1/C(=C2\Nc3ccccc3C2=O)Nc2ccccc21</smiles>

Figure 1.5 Selected historically relevant substituted arenes.

could be prepared via the decarboxylation of benzoic acid, flowers of benzoin (E. Mitscherlich, 1833), which in turn was obtained from gum benzoin [5]. Benzene was initially isolated and identified as a chemical compound from the condensed phase of pyrolyzed whale oil in 1825 by Michael Faraday [12]. However, it was not until the 1840s that benzene would be produced in an industrial environment based on its isolation from coal tar by Charles Mansfield in 1836.

Since their discovery during the 1860 s, electrophilic aromatic substitution reactions played the dominant role for functionalizations of arenes, and were often the method of choice for the synthesis of substituted arenes. For example, Hermann Kolbe, a student of Friedrich Wöhler, devised a synthesis for salicylic acid (7) $[13,14]$, which set the stage for the industrial preparation of acetylsalicylic acid (ASA, aspirin) (1) by Arthur Eichengrün and Felix Hoffmann at Bayer in 1897 (Scheme 1.2).

This representative historically relevant example, as with the industrial preparation of important dyes such as mauveine (Tyrian purple, 8) (1856, Perkin), alizarin (2) (1869, Perkin, Graebe and Liebermann) or indigo (9) (1890, Heumann) (Figure 1.5), illustrates the significant economical impact of aromatic substitution chemistry [15].

Modern aspects of electrophilic aromatic substitution chemistry address the development of enantioselective variants of these direct (hetero)arene functionalization reactions. For example, enantiomerically enriched metal catalysts, as well as organocatalysts, allowed for the asymmetric addition reactions of (hetero)arenes onto ( $\alpha, \beta$-unsaturated) carbonyl compounds. Additionally, highly enantioselective arylations of carbonyl compounds were accomplished with organometallic reagents 


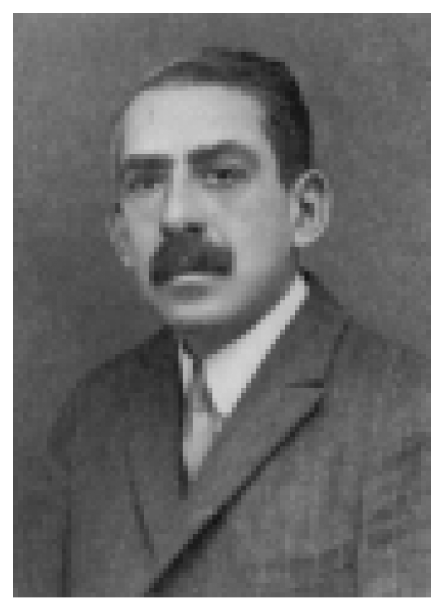

Figure 1.6 Fritz Ullmann (2 July 1875-17 March 1939).

as nucleophilic aryl donors. These exciting new methodologies of modern arylation chemistry are comprehensively reviewed by Christian Defieber and Erick M. Carreira in Chapter 8.

In addition to electrophilic aromatic substitution reactions, a variety of valuable approaches to the synthesis of substituted (hetero)arenes was developed [16]. Consequently, a fully comprehensive review on the entire history of arylation methodologies would call for an encyclopedia, and is, thus, beyond the scope of this introductory chapter. However, both metal-mediated and metal-catalyzed reactions $[17,18]$ had, arguably, the strongest impact on the development of modern arene syntheses $[19,20]$. While olefin metatheses reactions catalyzed by homogeneous catalysts proved to be particularly valuable for ring-closing reactions [21], late transition metal-catalyzed (cross)coupling reactions were among the most important chemical innovations of the twentieth century. Thus, the palladiumcatalyzed Tsuji-Trost reaction allowed for novel strategies in $\mathrm{C}-\mathrm{C}$ bond formations, which had a major impact on asymmetric syntheses [22]. The relevance of catalytic (cross)coupling chemistry is arguably most evident in (hetero)aryl(hetero)aryl and (hetero)aryl-heteroatom bond-forming reactions [17, 18, 23], and therefore the majority of the chapters in this book discuss recent innovations in this rapidly developing area of research. As a result, the following personal historical perspective focuses rather on the evolution of metal-catalyzed coupling chemistry.

While electrophilic substitution reactions enabled the direct functionalizations of (hetero)arenes, Fittig observed, during the nineteenth century, that halogenated arenes could be employed for the preparation of alkylated arenes in the presence of sodium under Wurtz's reaction conditions [24-26].

In 1901, Fritz Ullmann (Figure 1.6) showed that stoichiometric amounts of copper enabled the reductive coupling of haloarenes for the synthesis of symmetrically substituted biaryls (Scheme 1.3) [27]. 


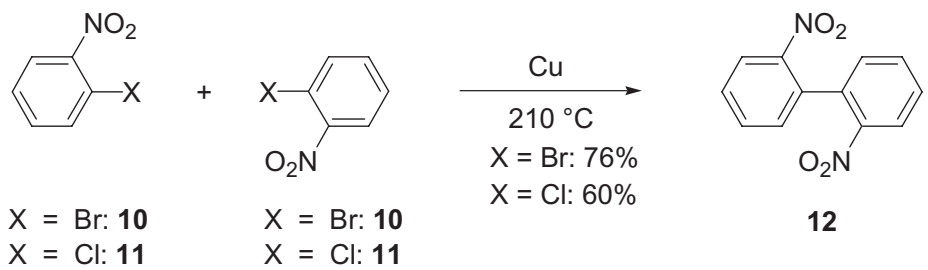

Scheme 1.3 Copper-mediated reductive coupling of haloarenes (Ullmann, 1901).<smiles>Cc1ccccc1N</smiles>

13<smiles>O=C(O)c1ccccc1Cl</smiles>

14

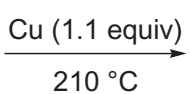

$90 \%$<smiles>Cc1ccccc1Nc1ccccc1C(=O)O</smiles>

15

Scheme 1.4 Copper-mediated arylation of amine 13 (Ullmann, 1903).<smiles>Oc1ccccc1</smiles>

16<smiles>Brc1ccccc1</smiles>

17

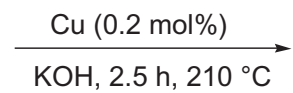

$90 \%$<smiles>c1ccc(Oc2ccccc2)cc1</smiles>

18

Scheme 1.5 Copper-catalyzed arylation of phenol (16) (Ullmann, 1905).

Based on these regioselective copper-mediated $\mathrm{C}-\mathrm{C}$ bond-forming reactions, Ullmann found in 1903 that arylations of amines were also viable when using haloarenes as coupling partners. Notably, this report illustrated at an early stage that chlorides could be employed as leaving groups on an arene, even for the conversion of more sterically hindered ortho-substituted starting materials (Scheme 1.4) [28].

These reports on copper-mediated coupling reactions set the stage for pioneering reports by Ullmann and Irma Goldberg (his later wife) on the use of catalytic amounts of copper for coupling reactions of haloarenes. Thus, the arylation of phenol (16) and its derivatives with low catalyst loadings of copper enabled the selective syntheses of diarylethers (Scheme 1.5) [29].

Importantly, Irma Goldberg showed in 1906 that copper-catalyzed arylation reactions of, potentially chelating, aniline derivatives could be achieved with bromoarenes as coupling partners (Scheme 1.6) [30].

It is noteworthy that this arylation protocol proved also applicable to catalytic transformations of amides as nucleophilic substrates (Scheme 1.7) [30].

Although these reports on copper-mediated and copper-catalyzed coupling reactions highlighted the potential of transition metal compounds for regioselective $\mathrm{C}-\mathrm{C}, \mathrm{C}-\mathrm{O}$ and $\mathrm{C}-\mathrm{N}$ bond formations, rather few further developments of these outstanding methodologies were disclosed during the following decades [31]. However, an improved understanding of organometallic reagents with umgepolte 
1.2 Syntheses of Substituted (Hetero)Arenes, and the Contents of this Book $\mid 7$<smiles>Nc1ccccc1C(=O)O</smiles>

19<smiles>Brc1ccccc1</smiles>

17

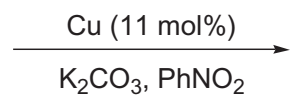

$3 \mathrm{~h}, 210^{\circ} \mathrm{C}$ $99 \%$<smiles>O=C(O)c1ccccc1Nc1ccccc1</smiles>

20

Scheme 1.6 Catalytic arylation of an aniline derivative (Goldberg, 1906).<smiles>NC(=O)c1ccccc1</smiles>

21<smiles>Brc1ccccc1</smiles>

17

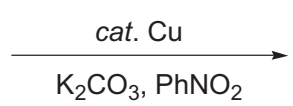

$2 \mathrm{~h}, 210^{\circ} \mathrm{C}$ $50 \%$<smiles>O=C(Nc1ccccc1)c1ccccc1</smiles>

22

Scheme 1.7 Copper-catalyzed arylation of amide 21 (Goldberg, 1906).

reactivity enabled André Job to disclose a catalytic effect of $\left[\mathrm{NiCl}_{2}\right]$ on the conversion of $\mathrm{PhMgBr}$ with ethylene and $\mathrm{CO}[32,33]$.

During the first half of the twentieth century, alternative methodologies for the preparation of arenes were discovered by Walter Reppe at the Badische Anilin-\&Soda-Fabrik (BASF), employing homogeneous metal catalysts. Thus, a scalable nickel-catalyzed synthesis of cyclooctatetraene from acetylene was devised [34]. While remarkable progress has been made in transition metal-catalyzed cycloaddition chemistry since these early reports [35], the achievement of satisfactory regioselectivities in the syntheses of unsymmetrically substituted (hetero)arenes still represents a major challenge when applying these methodologies [36].

During the 1940s, Kharasch and coworkers observed a dramatic influence of transition metal salts on the formation and reactivity of Grignard reagents [37]. It was found that catalytic amounts of $\left[\mathrm{CoCl}_{2}\right],\left[\mathrm{MnCl}_{2}\right],\left[\mathrm{FeCl}_{3}\right]$ or $\left[\mathrm{NiCl}_{2}\right]$ allowed for efficient homocouplings of organomagnesium reagents in the presence of organic halides, such as bromo- or chlorobenzene, which were thought to act as terminal oxidants (Scheme 1.8) [38].

Also during the 1940s, the formation of biphenyl (24) from fluorobenzene (26) and phenyl lithium (25) in an uncatalyzed reaction (Scheme 1.9) led Wittig to propose a dehydrobenzene, specifically an ortho-benzyne, as intermediate [39, 40], the formation of which was confirmed by Roberts in 1953 [41]. Modern arylation methodologies based on arynes as key intermediates are reviewed by $\mathrm{Yu}$ Chen and Richard Larock in Chapter 12.

Later, during the 1960s, selective cross-coupling reactions between alkyl, alkenyl or aryl halides and stoichiometric amounts of allyl nickel or alkyl copper reagents were developed (Scheme 1.10). These methodologies displayed a remarkable functional group tolerance and proved to be among the most effective protocols for $\mathrm{C}\left(\mathrm{sp}^{3}\right)-\mathrm{C}\left(\mathrm{sp}^{3}\right)$ cross-coupling reactions [42, 43]. A comprehensive review on metal-catalyzed cross-coupling reactions for challenging arylations of nonactivated 
<smiles>Br[Mg]Br</smiles>

23<smiles>Cc1ccc(Br)cc1</smiles>

23

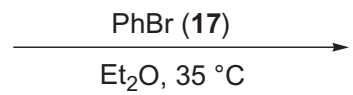

$\left[\mathrm{CoCl}_{2}\right](2.5 \mathrm{~mol} \%): 86 \%$

$\left[\mathrm{MnCl}_{2}\right]$ (4.0 mol\%): $21 \%$

$\left[\mathrm{FeCl}_{3}\right](5.0 \mathrm{~mol} \%): 47 \%$

$\left[\mathrm{NiCl}_{2}\right](4.0 \mathrm{~mol} \%): 72 \%$

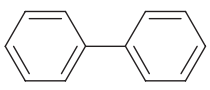

24

Scheme 1.8 Metal-catalyzed homocouplings of Grignard reagent 23 (Kharasch, 1941).

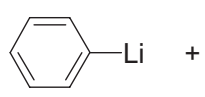

25

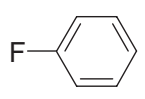

26

\section{$20 \mathrm{~h}, 35^{\circ} \mathrm{C}$}

$70 \%$

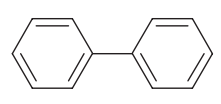

24

Scheme 1.9 Biphenyl synthesis through an aryne intermediate (Wittig, 1942).

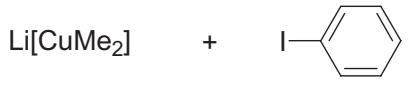

27
28

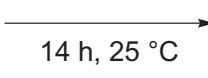

$90 \%$

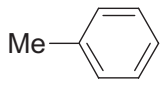

29

Scheme 1.10 Methylation of iodobenzene (28) with stoichiometric amounts of copper reagent 27 (Corey, 1967).

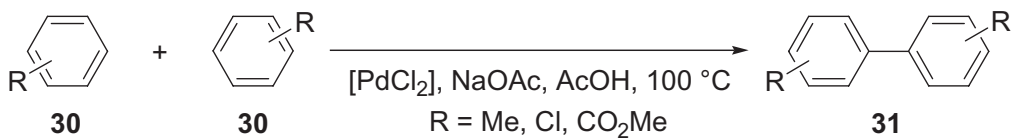

Scheme 1.11 Intermolecular oxidative homo-coupling (van Helden, Verberg, 1965).

alkyl-substituted electrophiles is provided by Masaharu Nakamura and Shingo Ito in Chapter 5.

In 1965, a palladium-mediated oxidative homo-coupling of arenes was reported. Through the use of $\left[\mathrm{PdCl}_{2}\right]$, along with sodium acetate as additive in acetic acid as solvent, biaryls could be obtained, with a regioselectivity being indicative of an electrophilic substitution-type mechanism (Scheme 1.11) [44]. Subsequently, a palladium-catalyzed dehydrogenative coupling of arenes was accomplished with oxygen as terminal oxidant $[45,46]$. Despite remarkable progress in oxidative biaryl syntheses, the achievement of chemoselectivity and regioselectivity in intermolecular cross-coupling reactions continues to offer a major challenge [47, 48].

In 1968, palladium-catalyzed oxidative arylations of alkenes using stoichiometric amounts of organometallic arylating agents, predominantly mercury-derived compounds, were disclosed by Heck [49]. These studies indicated that economical terminal oxidants, such as molecular oxygen, could be employed (Scheme 1.12) [49, 50]. Unfortunately, however, a significant limitation of this arylation protocol was represented by the use of highly toxic organomercury compounds [51]. In contrast, Fujiwara, Moritani and coworkers probed the use of stoichiometric amounts of 


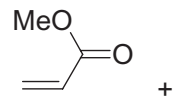

32<smiles>Cl[Hg]c1ccccc1</smiles>

33

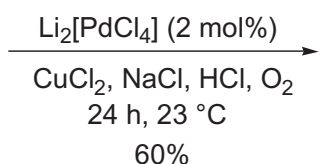

$60 \%$

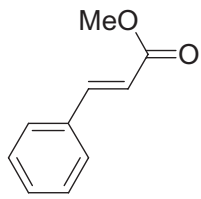

34

Scheme 1.12 Palladium-catalyzed oxidative arylation of alkenes (Heck, 1968).

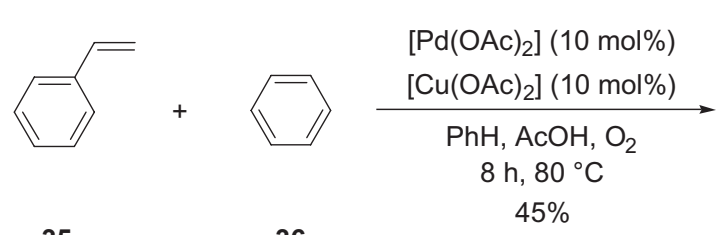

35 36

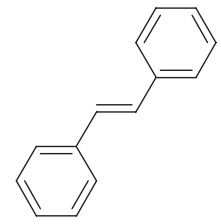

37

Scheme 1.13 Palladium-catalyzed oxidative arylation of alkenes with arenes (Fujiwara, Moritani, 1969).

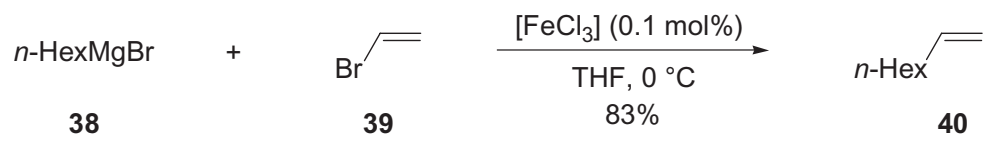

Scheme 1.14 Iron-catalyzed cross-coupling with alkenyl halide 39 (Kochi, 1971).

palladium compounds for a direct coupling between arenes and alkenes in 1967 $[52,53]$. Based on these stoichiometric transformations, a catalytic oxidative arylation of alkenes using simple arenes as arylating reagents was devised. Again, this intermolecular [54] catalytic $\mathrm{C}-\mathrm{H}$ bond functionalization could be achieved with inter alias molecular oxygen as terminal oxidant, and likely proceeded via an electrophilic aromatic substitution-type mechanism (Scheme 1.13) [55-57].

Another breakthrough in modern cross-coupling chemistry was accomplished during the early 1970s, when Kochi and coworkers disclosed a pioneering report in which electrophiles displayed $\mathrm{C}\left(\mathrm{sp}^{2}\right)-\mathrm{Br}$ bonds as functional groups. Interestingly, this iron-catalyzed cross-coupling was used for the functionalization of alkenyl bromides (Scheme 1.14) [58, 59], but was not applied to haloarenes as electrophiles until recently [60-63]. Nonetheless, Kochi's report highlighted the remarkable prospective applications of late transition metal complexes to $\mathrm{C}\left(\mathrm{sp}^{2}\right)-$ $\mathrm{C}\left(\mathrm{sp}^{2}\right)$ bond formations through catalytic cross-coupling chemistry.

A remarkable catalytic conversion of aryl halides was disclosed in 1971-namely the arylation of alkenes [64]-which can be considered as being related to Heck's arylations of alkenes with arylmercury, -tin or -lead compounds [49, 50]. Here, Mizoroki and coworkers found that catalytic amounts of $\left[\mathrm{PdCl}_{2}\right]$ or heterogeneous palladium black (41) enabled transformations of ethylene (42) or monosubstituted alkenes when using iodobenzene (28) as electrophile and KOAc as inorganic base (Scheme 1.15) [64, 65]. 


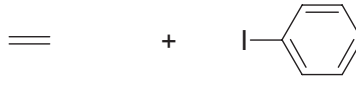

42

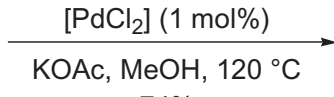

$74 \%$

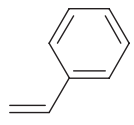

43

Scheme 1.15 Palladium-catalyzed arylation of alkene 42 (Mizoroki, 1971).

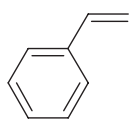

35

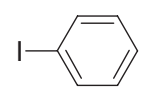

28

$$
\underset{\mathrm{NBu}_{3}, 2 \mathrm{~h}, 100{ }^{\circ} \mathrm{C}}{\stackrel{\left[\mathrm{Pd}(\mathrm{OAc})_{2}\right](1 \mathrm{~mol} \%)}{\longrightarrow}}
$$
$75 \%$

Scheme 1.16 Palladium-catalyzed arylation of styrene (35) (Heck, 1972).<smiles>[R]c1ccc([N+]Br)cc1</smiles>

44

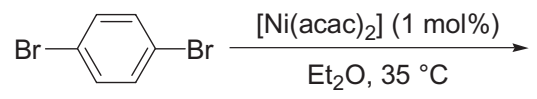

45

$$
\begin{aligned}
\mathrm{R} & =\mathrm{H}, \mathrm{Me} \\
& >80 \%
\end{aligned}
$$

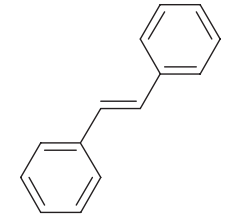

37

Scheme 1.17 Nickel-catalyzed $C_{\text {aryl }}-C_{\text {aryl }}$ cross-coupling (Corriu, 1972).

In 1972, Heck showed, independently, that aryl, benzyl and styryl halides would react with alkenes in the presence of a hindered amine as organic base at a lower reaction temperature of $100^{\circ} \mathrm{C}$ (Scheme 1.16) [51, 66]. A detailed overview on the modern aspects of Mizoroki-Heck reactions, as well as their oxidative variants (Fujiwara reactions), is provided by Martin Oestreich and Verena Trepohl in Chapter 7.

A catalytic $\mathrm{C}_{\text {aryl }}-\mathrm{C}_{\text {aryl }}$ cross-coupling was reported by Corriu and Masse in early 1972, when different nickel and cobalt compounds were probed in the crosscoupling between alkenyl or aryl bromides and aryl Grignard reagents, with $\left[\mathrm{Ni}(\mathrm{acac})_{2}\right]$, giving rise to superior results. For example, the catalytic cross-coupling of dibromide 45 provided high yields of the corresponding para-terphenyls 46 (Scheme 1.17) [33, 67].

Based on studies by Yamamoto on stoichiometric oxidative addition reactions of chlorobenzene to nickel complexes [68, 69], Kumada, Tamao and coworkers reported independently on highly efficient nickel-catalyzed cross-coupling reactions between Grignard reagents and aryl or alkenyl chlorides. Importantly, the beneficial effect of phosphine ligands, allowing for the effective cross-coupling reactions of chloroarenes, was demonstrated (Scheme 1.18) [70].

Furthermore, a catalytic cycle for this cross-coupling reaction was proposed that served as a blueprint for many subsequently developed transformations. The working mode of the catalytically competent species [TM] was based on: (a) an 


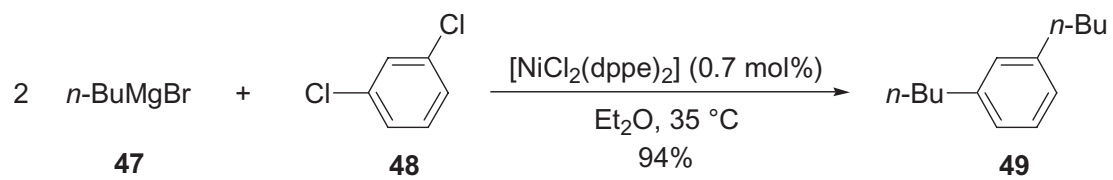

Scheme 1.18 Nickel-catalyzed cross-coupling of dichloride 48 (Kumada, Tamao, 1972).

(c) reductive elimination

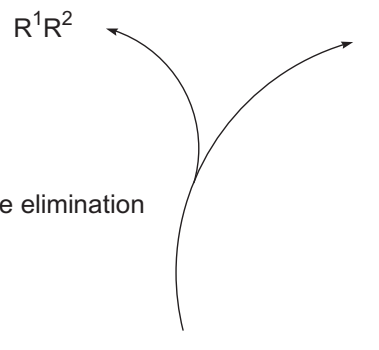

[TM]

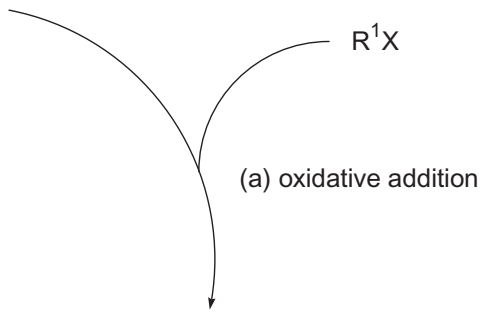

$\left[\mathrm{TM}^{\prime} \mathrm{R}_{\mathrm{X}}^{\mathrm{R}}\right.$

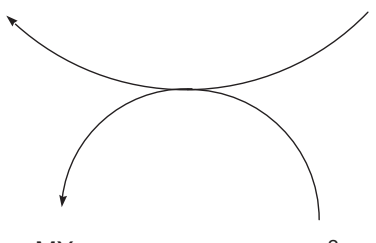

$\mathrm{MX}$

$M R^{2}$

(b) transmetallation

Scheme 1.19 Generalized catalytic cycle for metal-catalyzed cross-coupling reactions.

initial oxidative addition; (b) a subsequent transmetallation; and (c) a final reductive elimination, as illustrated in Scheme 1.19 [70, 71].

In 1975, both Cassar [72] and Murahashi and coworkers [73] reported on the applications of palladium complexes to catalytic cross-coupling chemistry [74]. Initially, Cassar compared nickel and palladium complexes in the catalytic crosscoupling between aryl or alkenyl halides and terminal alkynes, and found that nickel-based compounds exhibited no catalytic activity. In contrast, $\left[\mathrm{Pd}\left(\mathrm{PPh}_{3}\right)_{4}\right]$ enabled catalytic coupling reactions of various organic halides bearing $\mathrm{C}\left(\mathrm{sp}^{2}\right)-\mathrm{X}$ bonds as reactive functional groups, notably in the absence of any copper [75] additives (Scheme 1.20) [72].

At about the same time, Heck disclosed an independent report on a comparable palladium-catalyzed arylation of terminal alkynes. Here, the use of amines as bases allowed for the catalytic transformations of alkenyl and aryl halides, again in the absence of additional copper compounds (Scheme 1.21) [76].

Subsequently, Sonogashira and coworkers observed that the addition of catalytic amounts of [CuI] enabled arylations of terminal alkynes to proceed at significantly 


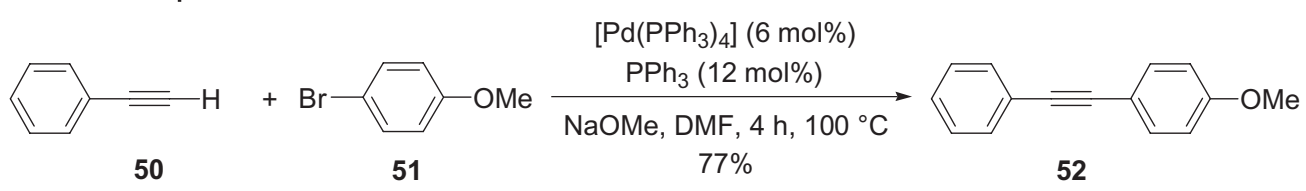

Scheme 1.20 Palladium-catalyzed synthesis of internal alkyne 52 (Cassar, 1975).

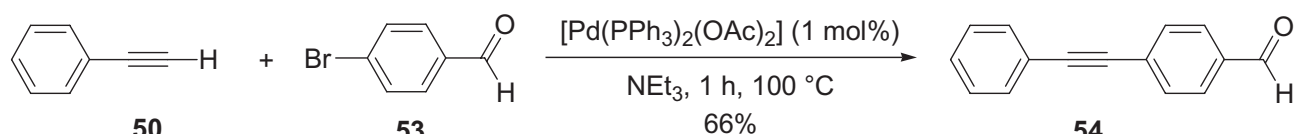

Scheme 1.21 Palladium-catalyzed arylation of terminal alkyne 50 (Heck, 1975).

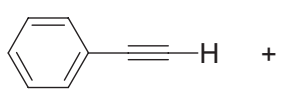

50

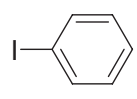

28

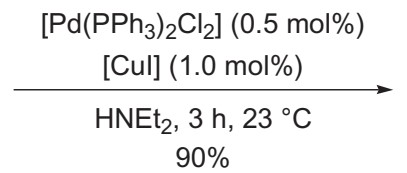

$90 \%$

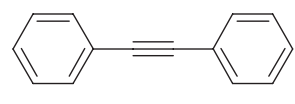

55

Scheme 1.22 Palladium-catalyzed arylation of terminal alkyne

50 in the presence of [Cul] (Sonogashira, 1975).

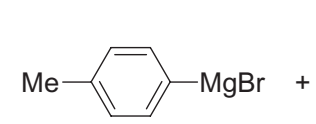

56

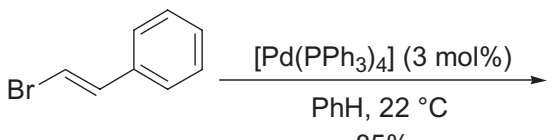

57<smiles>Cc1ccc(/C=C/c2ccccc2)cc1</smiles>

$85 \%$ i, 1975).

milder reaction conditions (Scheme 1.22) [77, 78]. Modern aspects of arylation reactions of alkynes, along with a detailed discussion on their mechanisms, are presented by Steven P. Nolan and Mihai S. Viciu in Chapter 6.

Also in 1975, Murahashi probed the use of palladium catalysts in cross-coupling reactions of alkenyl halides with lithium- or magnesium-based nucleophiles. While stoichiometric amounts of $\left[\mathrm{Pd}\left(\mathrm{PPh}_{3}\right)_{4}\right]$ were required for reactions with lithium derivatives as nucleophiles [79], the corresponding Grignard [80] reagents could be coupled with catalytic amounts of palladium complexes (Scheme 1.23) $[73,74]$.

Thus far, catalytic coupling reactions had focused on the use of magnesiumbased organometallics as nucleophiles. However, in 1976, Negishi revealed the use of alkenylalanes as valuable coupling partners for nickel- [81] (Scheme 1.24) or palladium-catalyzed [82] diastereoselective syntheses of substituted alkenes [83, 84]. These results showcased that organometallics other than Grignard reagents could be employed for efficient cross-coupling chemistry. Furthermore, a comparison between nickel- and palladium-based catalysts indicated the latter to be superior with respect to diastereoselective syntheses [83]. These observations set the stage for evaluating the scope of further organometallic reagents in palladium- 
1.2 Syntheses of Substituted (Hetero)Arenes, and the Contents of this Book 13<smiles>CCCCCCCCCCCCCCCCCCCCCCCCC</smiles>

59<smiles>Cc1ccc(Br)cc1</smiles>

60

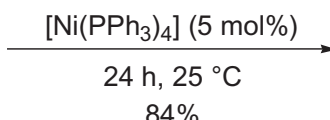

$84 \%$

Scheme 1.24 Nickel-catalyzed cross-coupling of alane 59 (Negishi, 1976).

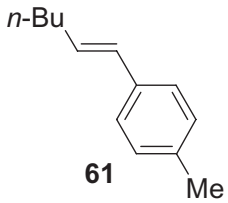

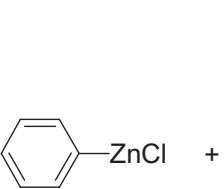

62

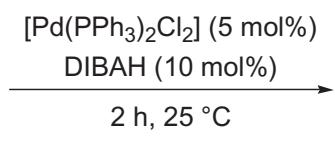

$74 \%$

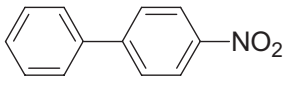

64

Scheme 1.25 Palladium-catalyzed cross-coupling with arylzinc 62 (Negishi, 1977).

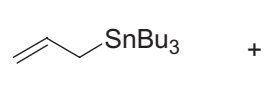

65<smiles>CC(=O)c1ccc(Br)cc1</smiles>

66

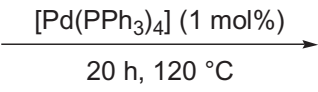

$98 \%$

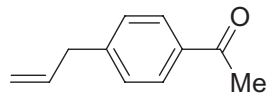

67

Scheme 1.26 Palladium-catalyzed cross-coupling with allyltin 65 (Kosugi, Migita, 1977).

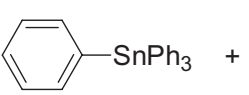

68<smiles>O=C(Cl)c1ccccc1</smiles>

69

$$
\frac{\left[\mathrm{BnPd}\left(\mathrm{PPh}_{3}\right)_{2} \mathrm{Cl}\right](1 \mathrm{~mol} \%)}{\mathrm{HMPA}, 60-65^{\circ} \mathrm{C}}
$$

$86 \%$

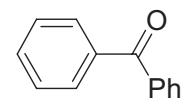

70

Scheme 1.27 Palladium-catalyzed arylation of acyl chloride 69 (Stille, 1978).

catalyzed cross-coupling chemistry. As a consequence, Negishi and coworkers disclosed catalytic arylations and alkenylations [85] of aryl halides using arylzinc reagents. The decreased nucleophilicity of organozinc compounds resulted in an excellent functional group tolerance (Scheme 1.25), particularly when compared to couplings with Grignard reagents [86-88].

Also in 1977, Kosugi, Migita and coworkers reported on the use of organotin compounds for the palladium-catalyzed cross-couplings of aryl [89] and acyl halides [90]. The allylation of haloarenes and the arylation of acyl halides displayed again a remarkable wide substrate scope (Scheme 1.26) [91].

Stille and Milstein showed, in 1978, that palladium-catalyzed arylations of acyl halides with aryltins occurred under exceedingly mild reactions conditions when using [ $\left.\mathrm{BnPd}\left(\mathrm{PPh}_{3}\right)_{2} \mathrm{Cl}\right]$ as catalyst (Scheme 1.27) [92]. Furthermore, Negishi developed inter alia palladium-catalyzed cross-coupling reactions between lithium 1-alkynyltributylborates and haloarenes [93], while Murahashi employed a transmetallation strategy for the use of trialkylboranes [94]. Suzuki, Miyaura and coworkers, in contrast, unraveled the beneficial effect of added bases in palladiumcatalyzed cross-coupling reactions between alkenylboranes and organic halides [95]. Importantly, mild bases (such as $\mathrm{Na}_{2} \mathrm{CO}_{3}$ ) enabled catalytic $\mathrm{C}_{\text {aryl }}-\mathrm{C}_{\text {aryl }}$ 


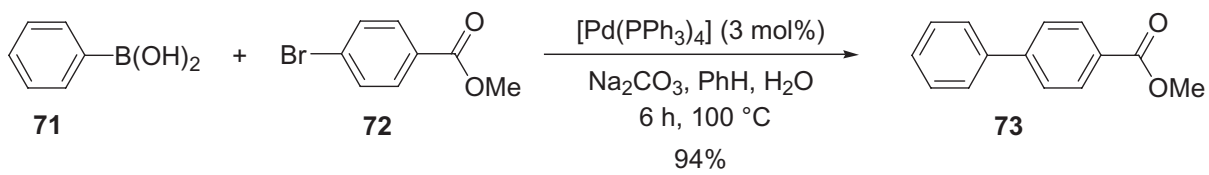

Scheme 1.28 Palladium-catalyzed arylation with phenyl boronic acid (71) (Suzuki, 1981).

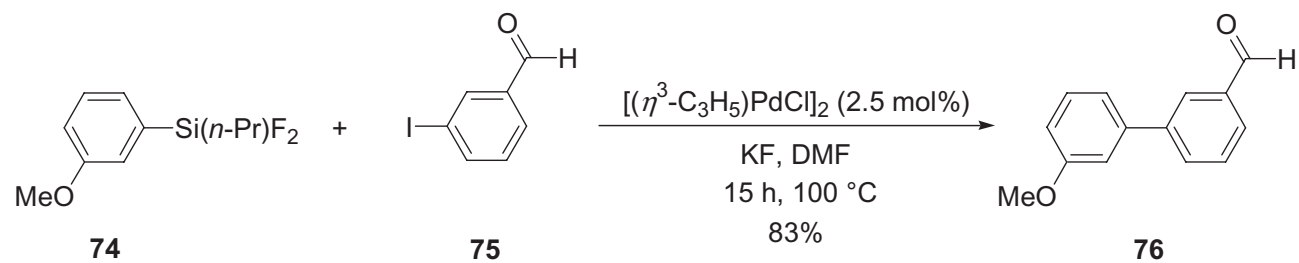

Scheme 1.29 Palladium-catalyzed arylation with silicon-based nucleophile 74 (Hiyama, 1989).

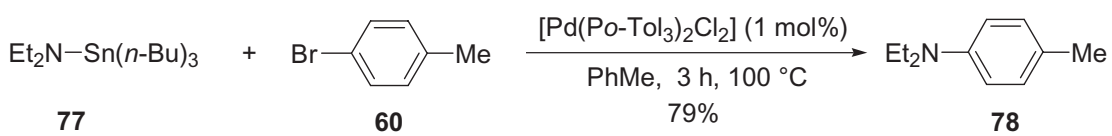

Scheme 1.30 Palladium-catalyzed arylation of tin amide 77 (Kosugi, Migita, 1983).

bond formations to proceed efficiently in aqueous reaction media (Scheme 1.28) [96, 97].

Cross-coupling reactions of alkenyl-substituted silicon-based nucleophiles were reported by Kumada [98], and by Hallberg in 1982 [99], as well as by Kikukawa subsequently [100]. However, efficient cross-couplings of aryl-substituted siliconbased nucleophiles were accomplished through the use of fluoride-containing additives, as reported by Hiyama in 1989. This in situ generation of pentacoordinated silicates gave rise to cross-couplings with a useful functional group tolerance (Scheme 1.29) [101, 102].

Further valuable catalytic cross-coupling reactions between organometallic reagents and aryl halides were reported, which matured to being indispensable tools in modern organic synthesis. In Chapter 2, Adam F. Littke summarizes the modern aspects of catalytic cross-coupling reactions, with particular focus on the use of challenging organic electrophiles, such as aryl chlorides, fluorides and tosylates, for $\mathrm{C}\left(\mathrm{sp}^{2}\right)-\mathrm{C}\left(\mathrm{sp}^{2}\right)$ bond formations.

In 1983, Kosugi, Migita and coworkers found that palladium-catalyzed aminations of bromoarenes could be achieved when tin amides were used as nucleophiles (Scheme 1.30) [103, 104].

In the 1990s, a breakthrough was independently accomplished by Buchwald [105] (Scheme 1.31) and Hartwig [106] (Scheme 1.32), establishing broadly applicable palladium-catalyzed Ullmann-type aminations of haloarenes, employing amines directly as nucleophiles. Thereby, the preparation and use of tin amides could be circumvented, and intramolecular [105] aminations of haloarenes were shown also to occur efficiently. 
1.2 Syntheses of Substituted (Hetero)Arenes, and the Contents of this Book $\mid 15$

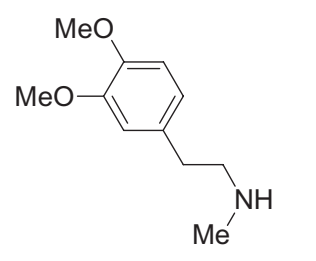

79

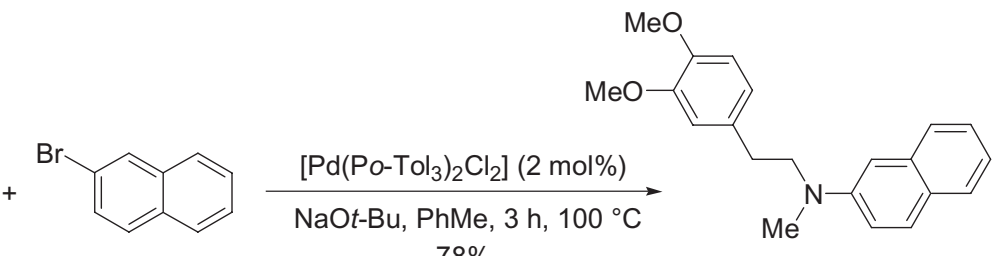

$78 \%$

Scheme 1.31 Palladium-catalyzed arylation of amine 79 (Buchwald, 1995).

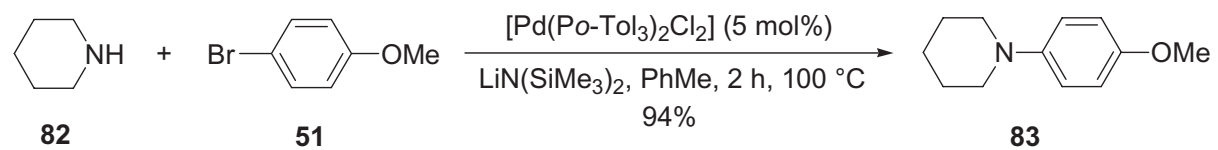

Scheme 1.32 Palladium-catalyzed arylation of amine 82 (Hartwig, 1995).

These palladium-catalyzed amination reactions of haloarenes are among the most popular modern methodologies for $\mathrm{C}\left(\mathrm{sp}^{2}\right)-\mathrm{N}$ bond formations. A detailed summary on the state of the art of these (also industrially relevant) reactions, as well as of related arylation reactions of $\alpha-\mathrm{C}-\mathrm{H}$ acidic compounds, is provided in Chapter 3 by Björn Schlummer and Ulrich Scholz.

In addition to Ullmann's copper-catalyzed [107] C $\left(\mathrm{sp}^{2}\right)-\mathrm{N}$ bond formations using haloarenes, a remarkable complementary approach was developed by Chan and Lam during the 1990s using boron-based arylating reagents [108, 109]. A detailed review by Andrew W. Thomas and Steven V. Ley on these oxidative coppermediated and copper-catalyzed arylations, as well as their extension to alcohols $[108,110]$, is to be found in Chapter 4 .

The presented methodologies for selective intermolecular $\mathrm{C}_{\text {aryl }}-\mathrm{C}_{\text {aryl }}$ bond formations largely relied on the use of prefunctionalized coupling partners as substrates. Predominantly, these transformations made use of organometallic reagents as nucleophilic coupling partners. An ecologically benign and economically attractive alternative is represented by the direct functionalization of $\mathrm{C}-\mathrm{H}$ bonds in simple arenes [111]. An early example of a metal-catalyzed direct arylation was disclosed in 1982 by Ames. During attempts directed towards palladium-catalyzed intermolecular arylation of alkene 85 following Heck's protocol, cyclization product 86 was obtained through an intramolecular direct arylation reaction (Scheme 1.33) [112].

An extension of this protocol showed that the alkene was not essential for achieving catalytic turnover. This allowed for syntheses of various important heterocycles, as illustrated for the preparation of dibenzofuran 88 in Scheme 1.34 [113-115].

In 1985, Ohta and coworkers reported on intermolecular direct arylations, and probed the palladium-catalyzed direct arylations of indole derivatives with electron- 
<smiles>Brc1nnc2ccccc2c1NC1=CC2CCC(C1)C2</smiles>

84<smiles>C=CC(=O)OCCCCCCOC(C)C</smiles>

85<smiles>c1ccc2c(c1)nnc1c3ccccc3[nH]c21</smiles>

86

$\mathrm{NEt}_{3}, \mathrm{MeCN}, 5 \mathrm{~h}, 150^{\circ} \mathrm{C}$

$55 \%$

Scheme 1.33 Palladium-catalyzed intramolecular direct arylation (Ames, 1982).<smiles>O=[N+]([O-])c1ccc(Oc2ccccc2Br)cc1</smiles>

87

$$
\begin{aligned}
& \underset{\mathrm{Na}_{2} \mathrm{CO}_{3}, \mathrm{DMA}, 2 \mathrm{~h}, 170{ }^{\circ} \mathrm{C}}{\stackrel{\left.\mathrm{Pd}(\mathrm{OAc})_{2}\right](10 \mathrm{~mol} \%)}{\longrightarrow}} \\
& 78 \%
\end{aligned}
$$<smiles>O=[N+]([O-])c1ccc2oc3ccccc3c2c1</smiles>

88

Scheme 1.34 Palladium-catalyzed intramolecular direct arylation for a dibenzofuran synthesis (Ames, 1983).<smiles>[R]n1ccc2ccccc21</smiles>

$\mathrm{R}=\mathrm{H}: \mathbf{8 9}$

$\mathrm{R}=\mathrm{Ts}: 90$

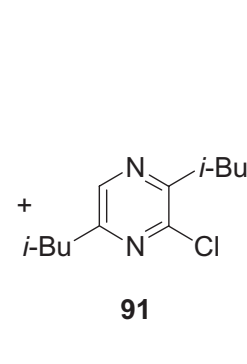

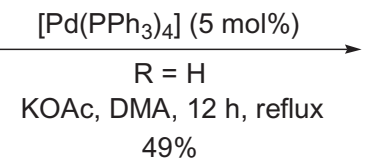

$\left[\mathrm{Pd}\left(\mathrm{PPh}_{3}\right)_{4}\right](8 \mathrm{~mol} \%)$ $\mathrm{R}=\mathrm{Ts}$

KOAc, DMA, $12 \mathrm{~h}$, reflux $68 \%$<smiles>CC(C)(C)c1cnc(C(C)(C)C)c(-c2cc3ccccc3[nH]2)n1</smiles>

92<smiles>Cn1cc(-c2nc(C(C)(C)C)cnc2C(C)(C)C)c2ccccc21</smiles>

Scheme 1.35 Palladium-catalyzed intermolecular direct arylation (Ohta, 1985 and 1989).

deficient heteroaryl chloride 91 . Interestingly, the regioselectivity of this intermolecular reaction was found to be strongly influenced by the substitution pattern of the indole on position N-1. Hence, indole (89) [116], as well as its N-alkylated derivatives [117], yielded the C-2 arylated products. In contrast, $N$-tosyl indole (90) gave rise to functionalization at position $\mathrm{C}-3$, with good to excellent regioselectivities (Scheme 1.35) [117].

During the following decades, palladium-catalyzed direct arylations proved to be valuable tools for organic synthesis, and a comprehensive review on these transformations is provided by Masahiro Miura and Tetsuya Satoh in Chapter 10. 
1.2 Syntheses of Substituted (Hetero)Arenes, and the Contents of this Book $\mid 17$

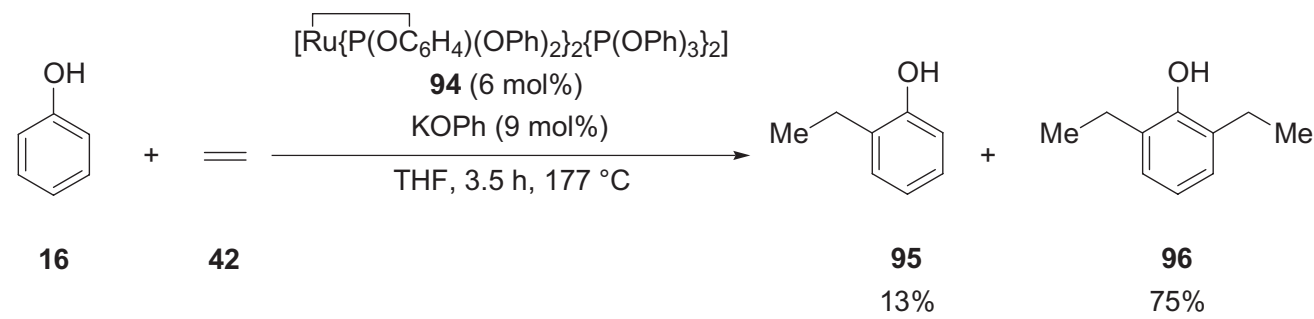

Scheme 1.36 Ruthenium-catalyzed alkylation of phenol (16) (Lewis, 1986).<smiles>CC(=O)c1ccccc1</smiles>

97<smiles>C=Cc1ccccc1C</smiles>

98
$\frac{\left[\mathrm{RuH}_{2}(\mathrm{CO})\left(\mathrm{PPh}_{3}\right)_{3}\right](2 \mathrm{~mol} \%)}{\text { PhMe, } 4 \mathrm{~h}, \text { reflux }}$ $66 \%$

Scheme 1.37 Ruthenium-catalyzed intermolecular C-H bond functionalization (Murai, 1993).

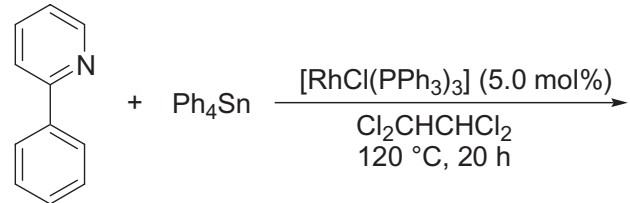

101

100

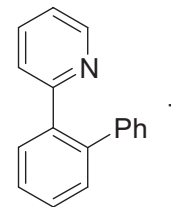

102

$56 \%$<smiles>CC(=O)c1ccccc1CCc1ccccc1C</smiles>

99

Scheme 1.38 Rhodium-catalyzed direct arylation of arene 100 (Oi, Inoue, 1998).

In 1986, a highly regioselective catalytic hydroarylation [118] of alkenes was disclosed by Lewis, whereby a cyclometallated ruthenium catalyst $\mathbf{9 4}$ allowed for a directed (hence ortho-selective) alkylation of phenols through the in situ formation of the corresponding phosphites (Scheme 1.36) [119].

In 1993, Murai reported on highly efficient alkylations of aromatic ketones with olefins, where $\left.\left[\mathrm{RuH}_{2}(\mathrm{CO}) \mathrm{PPh}_{3}\right)_{3}\right]$ served as the catalyst for regioselective $\mathrm{C}-\mathrm{H}$ bond functionalizations (Scheme 1.37) [120-123].

These examples illustrated the potential of ruthenium complexes for selective intermolecular $\mathrm{C}-\mathrm{H}$ bond functionalization reactions. Furthermore, they sowed the seeds of ruthenium-catalyzed direct arylation reactions, which proved to be rather broadly applicable [124-127].

A comparable concept was applied in 1998 to rhodium-catalyzed oxidative direct arylations, which employed organometallic compounds for regioselective direct arylations (Scheme 1.38) [128].

A comprehensive review on direct arylations with ruthenium and rhodium complexes is provided in Chapter 9 by Lutz Ackermann and Rubén Vicente, where 
recently reported iridium-, copper- and iron-catalyzed processes are also discussed. The current mechanistic understanding of transition metal-catalyzed direct arylation reactions is summarized in Chapter 11 by Paula de Mendoza and Antonio M. Echavarren.

A notable alternative to metal-catalyzed direct arylation reactions is represented by methodologies that involve the formation of radicals as intermediates. The modern aspects of these transformations, along with further synthetically useful radical-based arylation methods, such as the Meerwein arylation of alkenes [129], are reviewed in Chapter 13 by Santiago E. Vaillard, Birte Schulte and Armido Studer. In some cases, radical intermediates can be generated through photochemically initiated electron-transfer reactions and, given their ecologically and economically attractive features, these photochemical arylations are highly promising for future developments [130]. Significant progress was accomplished in this important research area [131], which is reviewed by Valentina Dichiarante, Maurizio Fagnoni and Angelo Albini in Chapter 14.

$\begin{array}{ll}\text { Abbreviations } \\ \text { acac } & \text { acetylacetonate } \\ \text { Ac } & \text { acetyl } \\ \text { atm } & \text { atmosphere } \\ \text { Bn } & \text { benzyl } \\ \text { Bu } & \text { butyl } \\ \text { cat } & \text { catalytic } \\ \text { DIBAH } & \text { diisobutylaluminum hydride } \\ \text { DMA } & \text { N,N-dimethylacetamide } \\ \text { DMF } & \text { N,N-dimethylformamide } \\ \text { dppe } & 1,2 \text {-bis(diphenylphosphino)ethane } \\ \text { Hex } & \text { hexyl } \\ \text { HMPA } & \text { hexamethylphosphoramide } \\ \text { NICS } & \text { nucleus-independent chemical shift } \\ \text { NMR } & \text { nuclear magnetic resonance } \\ \text { Ph } & \text { phenyl } \\ \text { Pr } & \text { propyl } \\ \text { THF } & \text { tetrahydrofuran } \\ \text { Tol } & \text { tolyl }\end{array}$

\section{References}

1 Loschmidt, J. (1861) Chemische Studien, A. Constitutions-Formeln der organischen Chemie in geographischer Darstellung, $B$. Das Mariotte'sche Gesetz, Wien.
2 Wiswesser, W.J. (1989) Aldrichim. Acta, 22, 17-19.

3 Anschütz, R. (1913) Konstitutions-Formeln der organischen Chemie in graphischer 
Darstellung, J. Loschmidt, republished in Ostwald's Klassiker der exakten Wissenschaft, Verlag von Wilhelm Engelmann, Leipzig.

4 (a) Kekulé, A. (1865) Bull. Soc. Chim. Fr., 3, 98-110;

(b) Kekulé, A. (1866) Liebigs Ann. Chem., 137, 129-96.

5 For alternative benzene structures, such as bicyclo[2.2.0]hexa-2,5-diene, originally reported by Sir James Dewar in 1867 , as well as for a detailed historical review on benzene structures, see: (a) Astruc, D. (2002) Arene chemistry: from historical notes to the state of the art, in Modern Arene Chemistry (ed. D. Astruc), Wiley-VCH Verlag GmbH, Weinheim, pp. 1-19;

(b) Rocke, A.J. (1985) Ann. Sci., 42, 355-81.

6 Selected reviews on aromaticity and antiaromaticity: (a) Badger, G.M. (1969) Aromatic Character and Aromaticity, University Press, Cambridge;

(b) Breslow, R. (1973) Acc. Chem. Res., 6, 393-8;

(c) Agranat, I. (1973) Theoretical aromatic chemistry, in MTP International Review of Science, Organic Chemistry, Series One, Aromatic Compounds, Vol. 3 (ed. H. Zollinger), Butterworths, London, pp. 139-77; (d) Agranat, I. and Barak, A. (1976) The controversial notion of aromaticity, in MTP International Review of Science, Organic Chemistry, Series One, Aromatic Compounds, Vol. 3 (ed. H. Zollinger), Butterworths, London, pp. 1-177; (e) Garratt, P.J. (1986) Aromaticity, John Wiley \& Sons, Inc., New York;

(f) Minkin, V.I., Glukhovtsev, M.N. and Simkin, B.Y. (1994) Aromaticity and Antiaromaticity: Electronic and Structural Aspects, John Wiley \& Sons, Inc., New York;

(g) Schleyer, P.v.R. and Jiao, H.J. (1996) Pure Appl. Chem., 68, 209-18;

(h) special issue on aromaticity:

Schleyer, P.v.R. (ed.) (2001) Chem. Rev., 101, $1115 \mathrm{ff}$;

(i) Balaban, A.T., Oniciu, D.C. and Katritzky, A.R. (2004) Chem. Rev., 104, 2777-812;

\section{References 19}

(j) Special issue on delocalization-pi and sigma: Schleyer, P.v.R. (ed.) (2005) Chem. Rev., 105, $3433 \mathrm{ff}$.

7 Hückel, E. (1931) Z. Phys., 70, 204-86.

8 For a recent report on the remarkable synthesis of a Möbius [16] annulene, see: Ajami, D., Oeckler, O., Simon, A., Herges, R. (2003) Nature, 426, 819-21.

9 Krygowski, T.M. and Cyranski, M.K. (2001) Chem. Rev., 101, 1385-419.

10 For Nucleus-Independent Chemical Shifts (NICS) as a simple and efficient aromaticity probe, see: (a) Schleyer, P.v.R., Maerker, C., Dransfeld, A., Jiao, H. and Hommes, N.J.v.E. (1996) J. Am. Chem. Soc., 118, 6317-18; (b) Chen, Z., Wannere, C.S., Corminboeuf, C., Puchta, R. and Schleyer, P.v.R. (2005) Chem. Rev., 105, 3842-88.

11 Note that the concept of aromaticity continues to be a valuable stimulus for the development of chemical bond theory, and that some aspects of aromaticity are still controversially discussed: (a) Pogodin, S. and Agranat, I. (2007) J. Org. Chem., 72, 10096-107;

(b) Mills, N.S. and Llagostera, K.B. (2007)

J. Org. Chem., 72, 9163-9;

(c) Wannere, C.S., Sattelmeyer, K.W., Schaefer, H.F., III and Schleyer, P.v.R. (2004) Angew. Chem. Int. Ed., 43, 4200-6; (d) Seal, P. and Chakrabarti, S. (2007) J. Phys. Chem. A, 111, 9988-94.

12 Faraday, M. (1825) Philos. Trans. R. Soc. Lond., 115, 440-66.

13 Kolbe, H. (1860) Justus Liebigs Ann. Chem., 113, 125-7.

14 Charles Frédéric Gerhardt prepared acetylsalicylic acid in 1853, though not in pure form: (a) Gerhardt, C.F. (1853) Ann. Chem. Pharm., 87, 149-79;

(b) Gerhardt, C.F. (1853) Justus Liebigs Ann. Chem., 87, 57-84.

15 For further illustrative examples, see for example: Nicolaou, K.C. and Mantagnon, T. (2008) Molecules that Changed the World, Wiley-VCH Verlag GmbH, Weinheim.

16 Astruc, D. (ed.) (2002) Modern Arene Chemistry, Wiley-VCH Verlag $\mathrm{GmbH}$, Weinheim. 
17 A valuable access to substituted arenes was also provided with the development of the chromium-templated Dötzreaction: Dötz, K.H. and Stendal, J., Jr (2002) The chromium-templated carbene benzannulation approach to densely functionalized arenes (Dötz reaction), in, Modern Arene Chemistry (ed. D. Astruc), Wiley-VCH Verlag GmbH, pp. 250-96.

18 For regioselective functionalizations of substituted arenes through directed ortho-metallation reactions with stoichiometric amounts of organometallic bases, see: (a) Snieckus, V. and Macklin, T. (2005) Metallation of arenes. Directed ortho and remote metallation (DoM and DreM), in Handbook of C-H Transformations (ed. G. Dyker), Wiley-VCH Verlag $\mathrm{GmbH}$, Weinheim, pp. 106-18;

(b) Hartung, C.G. and Snieckus, V. (2002) The directed ortho metallation reaction-a point of departure of new synthetic aromatic chemistry, in Modern Arene Chemistry (ed. D. Astruc), WileyVCH Verlag GmbH, pp. 330-67.

19 For reviews, see: (a) de Meijere, A. and Diederich, F. (eds) (2004) MetalCatalyzed Cross-Coupling Reactions, 2nd edn, Wiley-VCH Verlag GmbH, Weinheim;

(b) Beller, M. and Bolm, C. (eds) (2004) Transition Metals for Organic Synthesis, 2nd edn, Wiley-VCH Verlag GmbH, Weinheim.

20 The potential of cross-coupling chemistry was among others illustrated by their applications to various syntheses of complex natural products: Nicolaou, K.C., Bulger, P.G. and Sarlah, D. (2005) Angew. Chem. Int. Ed., 44, 4442-89.

21 A review on syntheses of aromatic compounds based on ring-closing metathesis: Donohoe, T.J., Orr, A.J. and Bingham, M. (2006) Angew. Chem. Int. Ed., 45, 2664-70.

22 Tsuji, J. (2004) Palladium Reagents and Catalysts, 2nd edn, John Wiley \& Sons, Ltd, Chichester.

23 Hassan, J., Sevignon, M., Gozzi, C., Schulz, E. and Lemaire, M. (2002) Chem. Rev., 102, 1359-469.
24 Wurtz, A. (1855) Justus Liebigs Ann. Chem., 96, 364-75.

25 Tollens, B. and Fittig, R. (1864) Justus Liebigs Ann. Chem., 131, 303-23.

26 Fittig, R. (1862) Justus Liebigs Ann. Chem., 121, 361-5.

27 Ullmann, F. and Bielecki, J. (1901) Chem. Ber., 34, 2174-85.

28 Ullmann, F. (1903) Chem. Ber., 36, 2382-4.

29 Ullmann, F. and Sponagel, P. (1905) Chem. Ber., 38, 2211-12.

30 Goldberg, I. (1906) Chem. Ber., 39, 1691-2.

31 For an early example of palladiumcatalyzed reductive homocouplings of haloarenes in the presence of hydrazine, see: Busch, M. and Schmidt, W. (1929) Chem. Ber., 62, 2612-20.

32 Job, A. and Reich, R. (1924) C. R. Hebd. Seances Acad. Sci., 179, 330-2.

33 Corriu, R.J.P. (2002) J. Organomet. Chem., 653, 20-2.

34 (a) Reppe, W. (1949) Neue Entwicklungen auf dem Gebiet der Chemie des Acetylen und Kohlenoxyds, Springer, BerlinGöttingen-Heidelberg;

(b) For a recent computational study, see Straub, B.F. and Gollub, C. (2004) Chem. Eur. J., 10, 3081-90.

35 (a) For representative recent examples, see: Nishida, G., Noguchi, K., Hirano, M. and Tanaka, K. (2008) Angew. Chem. Int. Ed., 47, 3410-13;

(b) Hilt, G. and Janikowski, J. (2008) Angew. Chem. Int. Ed., 47, 5243-5; (c) Barluenga, J., Fernández-Rodríguez, M.A., García-García, P. and Aguilar, E. (2008), J. Am. Chem. Soc., 130, 2764-5;

(d) Wender, P.A. and Christy, J.P. (2007) J. Am. Chem. Soc., 129, 13402-3; and references cited therein.

36 For reviews, see: (a) Grotjahn, D.B. (1995) Comprehensive Organometallic Chemistry II, Vol. 12 (eds L.S. Hegedus, E.W. Abel, F.G.A. Stone and G. Wilkinson), Pergamon, Oxford, pp. 741-70;

(b) Bönnemann, H. and Brijoux, W. (2004) Transition Metals for Organic Synthesis, 2nd edn (eds M. Beller and C. Bolm), Wiley-VCH Verlag GmbH, Weinheim, pp. 171-97;

(c) Nakamura, I. and Yamamoto, Y. (2004) Chem. Rev., 104, 2127-98. 
37 Kharasch, M.S. and Reinmuth, O. (1954) Grignard Reagents of Nonmetallic Substances, Prentice-Hall, Inc., New York.

38 Kharasch, M.S. and Fields, E.K. (1941) J. Am. Chem. Soc., 63, 2316-20.

39 Wittig, G. (1942) Naturwissenschaften, 30, 696-703.

40 For the identification of 1,4-diradicals in the Bergman cyclization, see: Jones, R.R. and Bergman, R.G. (1972) J. Am. Chem. Soc., 94, 660-1.

41 Roberts, J.D., Simmons, J., Carlsmith, L.A. and Vaughan, C.W. (1953) J. Am. Chem. Soc., 75, 3290-1.

42 For selective cross-coupling reactions between haloarenes and stoichiometric amounts of allyl nickel reagents, see: (a) Corey, E.J. and Semmelhack, M.F. (1967) J. Am. Chem. Soc., 89, 2755-7; (b) For cross-couplings with alkyl copper compounds, see: Corey, E.J. and Posner, G.H. (1967) J. Am. Chem. Soc., 89, 3911-12;

(c) Corey, E.J. and Posner, G.H. (1968) J. Am. Chem. Soc., 90, 5615.

43 Posner, G.H. (1975) Org. React., 22 , 253-400.

44 van Helden, R. and Verberg, G. (1965) Recl. Trav. Chim. Pays-Bas, 84, 1263-73.

45 Iataaki, H. and Yoshimoto, H. (1973) J. Org. Chem., 38, 76-9.

46 See also: (a) Yoshimoto, H. and Itatani, H. (1973) J. Catal., 31, 8-12;

(b) Clark, F.R.S., Norman, R.O.C., Thomas, C.B. and Willson, J.S. (1974) J. Chem. Soc., Perkin Trans., 11, 1289-94.

47 Beccalli, E.M., Broggini, G., Martinelli, M. and Sottocornola, S. (2007) Chem. Rev., 107, 5318-65.

48 For a recent example of selective intermolecular oxidative palladiumcatalyzed cross-coupling between indoles and arenes, see: Stuart, D.R. and Fagnou, K. (2007) Science, 316, 1172-5.

49 Heck, R.F. (1968) J. Am. Chem. Soc., 90, 5518-26.

50 Heck, R.F. (1969) J. Am. Chem. Soc., 91, 6707-14.

51 Heck, R.F. (2006) Synlett, 2855-60.

52 Moritani, I. and Fujiwara, Y. (1967) Tetrahedron Lett., 8, 1119-22.
53 Fujiwara, Y., Moritani, I. and Matsuda, M. (1968) Tetrahedron, 24, 4819-24.

54 For selected examples of intramolecular variants, see: (a) Iida, H., Yuasa, Y. and Kibayashi, C. (1980) J. Org. Chem., 45, 2938-42;

(b) Knölker, H.-J. and O'Sullivan, N. (1994) Tetrahedron, 50, 10893-908.;

(c) Hagelin, H., Oslob, J.D. and Akermark, B. (1999) Chem. Eur. J., 5 , 2413-16; and cited references.

55 Fujiwara, Y., Moritani, I., Danno, S., Asano, R. and Teranishi, S. (1969) J. Am. Chem. Soc., 91, 7166-9.

56 Jia, C., Kitamura, T. and Fujiwara, Y. (2001) Acc. Chem. Res., 34, 633-9.

57 Fujiwara, Y. and Kitamura, T. (2005) Fujiwara reaction: palladium-catalyzed hydroarylations of alkynes and alkenes, in Handbook of C-H Transformations (ed. G. Dyker), Wiley-VCH Verlag GmbH, pp. 194-202.

58 Tamura, M. and Kochi, J. (1971) J. Am. Chem. Soc., 93, 1487-9.

59 Tamura, M. and Kochi, J. (1971) Synthesis, 303-5.

60 Fürstner, A. and Leitner, A. (2002) Angew. Chem. Int. Ed., 41, 609-12.

61 Sherry, B.D. and Fürstner, A. (2008) Acc. Chem. Res., 41, DOI: 10.1021/ar 800039X

62 (a) Correa, A., García Mancheño, O. and Bolm, C. (2008) Chem. Soc. Rev., 37, 1108-17;

(b) Bolm, C., Legros, J. and Zani, L. (2004) Chem. Rev., 104, 6217-54.

63 Note that iron-catalyzed $\mathrm{C}_{\text {aryl }}-\mathrm{C}_{\text {aryl }}$ crosscoupling reactions are still challenging. For recent reports on such coupling reactions, see: (a) Sapountzis, I., Lin, W., Kofink, C.C., Despotopoulou, C. and Knochel, P. (2005) Angew. Chem. Int. Ed., 44, 1654-8;

(b) Hatakeyama, T. and Nakamura, M. (2007) J. Am. Chem. Soc., 129, 9844-5.

64 Mizoroki, T., Mori, K. and Ozaki, A. (1971) Bull. Chem. Soc. Jpn, 44, 581.

65 Mori, K., Mizoroki, T. and Ozaki, A. (1973) Bull. Chem. Soc. Jpn, 46, 1505-8.

66 Heck, R.F. and Nolley, J.P., Jr (1972) J. Org. Chem., 37, 2320-2.

67 Corriu, R.J.P. and Masse, J.P. (1972) J. Chem. Soc., Chem. Commun., 144. 
68 Uchino, M., Yamamoto, A. and Ikeda, S. (1970) J. Organomet. Chem., 24, C63-4.

69 Yamamoto, A. (2002) J. Organomet. Chem., 653, 5-10.

70 Tamao, K., Sumitani, K. and Kumada, M. (1972) J. Am. Chem. Soc., 94, 4374-6.

71 Tamao, K. (2002) J. Organomet. Chem., 653, 23-6.

72 Cassar, L. (1975) J. Organomet. Chem., 93, 253-7.

73 Yamamura, M., Moritani, I. and Murahashi, S.-I. (1975) J. Organomet. Chem., 91, C39-42.

74 Murahashi, S.-I. (2002) J. Organomet. Chem., 653, 27-33.

75 For cross-coupling reactions between iodoarenes and stoichiometric amounts of copper acetylides in the absence of palladium compounds, see: (a) Castro, C.E. and Stephens, R.D. (1963) J. Org. Chem., 28, 2163;

(b) Castro, C.E., Gaughan, E.J. and Owsley, D.C. (1966) J. Org. Chem., 31, 4071-8.

76 Dieck, H.A. and Heck, R.F. (1975) J. Organomet. Chem., 93, 259-63.

77 Sonogashira, K., Tohda, Y. and Hagihara, N. (1975) Tetrahedron Lett., 50, 4467-70.

78 Sonogashira, K. (2002) J. Organomet. Chem., 653, 46-9.

79 In 1979, palladium-catalyzed crosscouplings with organolithium compounds were reported: Murahashi, S.-I., Yamamura, M., Yanagisawa, K.-I., Mita, N. and Kondo, K. (1979) J. Org. Chem., 44, 2408-17.

80 For further early examples of palladium-catalyzed cross-coupling reactions of Grignard reagents, see: (a) Fauvarque, J.F. and Jutand, A. (1976) Bull. Soc. Chem. Fr., 765-70; (b) Sekiya, A. and Ishikawa, N. (1976) J. Organomet. Chem., 118, 349-54.

81 Negishi, E.-i. and Baba, S. (1976) J. Chem. Soc. Chem. Commun., 596-7.

82 Baba, S. and Negishi, E.-i. (1976) J. Am. Chem. Soc., 98, 6729-31.

83 Negishi, E.-i. (2002) J. Organomet. Chem., 653, 34-40.

84 Negishi, E.-i. (2007) Bull. Chem. Soc. Jpn, 80, 233-57.
85 King, A.O., Okukado, N., Negishi, E.-i. (1977) J. Chem. Soc. Chem. Commun., 19, 683-4.

86 Negishi, E.-i. and King, A.O. (1977) J. Org. Chem., 42, 1821-3.

87 See also: Fauvarque, J.F. and Jutand, A. (1977) J. Organomet. Chem., 132, C17-19.

88 For cross-coupling reactions with zirconium-based nucleophiles, see: Negishi, E.-i. and Van Horn, D.E. (1977) J. Am. Chem. Soc., 99, 3168-70.

89 Kosugi, M., Sasazawa, K., Shimizu, Y. and Migita, T. (1977) Chem. Lett., 301-2.

90 Kosugi, M., Shimizu, Y. and Migita, T. (1977) Chem. Lett., 1423-4.

91 Kosugi, M. and Fugami, K. (2002) J. Organomet. Chem., 653, 50-3.

92 Milstein, D. and Stille, J.K. (1978) J. Am. Chem. Soc., 100, 3636-8.

93 Negishi, E.-i. (1982) Acc. Chem. Res., 15, 340-8.

94 Kondo, K. and Murahashi, S.-I. (1979) Tetrahedron Lett., 20, 1237-40.

95 Miyaura, N., Yamada, K. and Suzuki, A. (1979) Tetrahedron Lett., 20, 3437-40.

96 Miyaura, N., Yanagi, T. and Suzuki, A. (1981) Synth. Commun., 11, 513-19.

97 Miyaura, N. (2002) J. Organomet. Chem., 653, 54-7.

98 Yoshida, J.-i., Tamao, K., Yamamoto, H. Kakui, T., Uchida, T. and Kumada, M. (1982) Organometallics, 1, 542-9.

99 Hallberg, A. and Westerlund, C. (1982) Chem. Lett., 1993-4.

100 Kikukawa, K., Ikenaga, K., Wada, F. and Matsuda, T. (1983) Chem. Lett., 1337-40.

101 Hatanaka, Y., Fukushima, S. and Hiyama, T. (1989) Chem. Lett., 1711-14.

102 Hiyama, T. (2002) J. Organomet. Chem., 653, 58-61.

103 Kosugi, M., Kameyama, M. and Migita, T. (1983) Chem. Lett., 927-8.

104 For palladium-catalyzed amidations of haloarenes using $\mathrm{CO}$ and anilines, see: Schoenberg, A. and Heck, R.F. (1974) J. Org. Chem., 39, 3327-31.

105 Guram, A.S., Rennels, R.A. and Buchwald, S.L. (1995) Angew. Chem. Int. Ed. Engl., 34, 1348-50.

106 Louie, J. and Hartwig, J.F. (1995) Tetrahedron Lett., 36, 3609-12.

107 For selected recent examples of nickelcatalyzed aminations of haloarenes, see: 
(a) Gao, C.-Y. and Yang, L.-M. (2008)

J. Org. Chem., 73, 1624-7;

(b) Matsubara, K., Ueno, K., Koga, Y. and Hara, K. (2007) J. Org. Chem., 72, 5069-76;

(c) Wolfe, J.P. and Buchwald, S.L. (1997) J. Am. Chem. Soc., 119, 6054-8;

(d) Lipshutz, B.H. and Ueada, H. (2000) Angew. Chem. Int. Ed., 39, 4492-4;

(e) Brenner, E., Schneider, R. and Fort, Y. (1999) Tetrahedron, 55, 12829-42;

(f) Desmarets, C., Schneider, R. and

Fort, Y. (2002) J. Org. Chem., 67, 302936; and references cited therein.

108 Chan, D.M.T., Monaco, K.L., Wang, R.-P. and Winters, M.P. (1998) Tetrahedron Lett., 39, 2933-6.

109 Lam, P.Y.S., Clark, C.G., Saubern, S., Adams, J., Winters, M.P., Chan, D.M.T. and Combs, A. (1998) Tetrahedron Lett., 39, 2941-4.

110 Evans, D.A., Katz, J.L. and West, T.R. (1998) Tetrahedron Lett., 39, 2937-40.

111 For recent reviews, see: (a) Li, B.-J., Yang, S.-D. and Shi, Z.-J. (2008) Synlett, 949-57;

(b) Ackermann, L. (2007) Top.

Organomet. Chem., 24, 35-60;

(c) Satoh, T. and Miura, M. (2007) Top.

Organomet. Chem., 24, 61-84;

(d) Alberico, D., Scott, M.E. and Lautens, M. (2007) Chem. Rev., 107, 174-238;

(e) Bergman, R.G. (2007) Nature, 446, 391-3;

(f) Campeau, L.-C., Stuart, D.R. and Fagnou, K. (2007) Aldrichim. Acta, 40, 35-41;

(g) Seregin, I.V. and Gevorgyan, V. (2007) Chem. Soc. Rev., 36, 1173-93; (h) Daugulis, O., Zaitsev, V.G., Shabashov, D., Pham, Q.N. and Lazareva, A. (2006) Synlett, 3382-8; (i) Yu, J.-Q., Giri, R. and Chen, X. (2006) Org. Biomol. Chem., 4, 4041-7.

112 Ames, D.E. and Bull, D. (1982) Tetrahedron, 38, 383-7.

113 Ames, D.E. and Opalko, A. (1983) Synthesis, 234-5.

114 Ames, D.E. and Opalko, A. (1984) Tetrahedron, 40, 1919-25.

115 Interestingly, an intramolecular palladium-catalyzed oxidative arylation for a dibenzofuran synthesis was reported earlier: Shiotani, A. and
Itatani, H. (1974), Angew. Chem. Int. Ed., 13, 471-2.

116 Akita, Y., Inoue, A., Yamamoto, K., Ohta, A., Kurihara, T. and Shimizu, M. (1985) Heterocycles, 23, 2327-33.

117 Akita, Y., Itagaki, Y., Takizawa, S. and Ohta, A. (1989) Chem. Pharm. Bull., 37, 1477-80.

118 For recent reviews on catalytic hydroarylation reactions, see: (a) Bandini, M., Emer, E., Tommasi, S. and UmaniRonchi, A. (2006) Eur. J. Org. Chem., 3527-44;

(b) Nevado, C. and Echavarren, A.M. (2005) Synthesis, 167-82;

(c) Liu, C., Bender, C.F., Han, X. and Widenhoefer, R.A. (2007) Chem.

Commun., 3607-18;

(d) Kakiuchi, F. and Chatani, N. (2003) Adv. Synth. Catal., 345, 1077-101, and references cited therein.

119 Lewis, L.N. and Smith, J.F. (1986) J. Am. Chem. Soc., 108, 2728-35.

120 Murai, S., Kakiuchi, F., Sekine, S., Tanaka, Y., Kamatani, A., Sonoda, M. and Chatani, N. (1993) Nature, 366, 529-31.

121 Kakiuchi, F. and Murai, S. (2002) Acc. Chem. Res., 35, 826-34.

122 Kakiuchi, F. and Chatani, N. (2004) Ruthenium Catalysts and Fine Chemistry (ed. C. Bruneau and P.H. Dixneuf), Springer, Berlin, Heidelberg, pp. 45-79.

123 Kakiuchi, F. and Chatani, N. (2004) Ruthenium in Organic Synthesis (ed. S.-I. Murahashi), Wiley-VCH Verlag $\mathrm{GmbH}$, Weinheim, pp. 219-55.

124 Oi, S., Fukita, S., Hirata, N., Watanuki, N., Miyano, S. and Inoue, Y. (2001) Org. Lett., 3, 2579-81.

125 Ackermann, L. (2005) Org. Lett., 7, 3123-5.

126 Oi, S., Sakai, K. and Inoue, Y. (2005) Org. Lett., 7, 4009-11.

127 Ackermann, L., Althammer, A. and Born, R. (2006) Angew. Chem. Int. Ed., 45, 2619-22.

128 Oi, S., Fukita, S. and Inoue, Y. (1998) Chem. Commun., 2439-40.

129 Meerwein, H., Büchner, E. and van Emster, K. (1939) J. Prakt. Chem., 152 , 237-66.

130 Dichiarante, V., Fagnoni, M. and Albini, A. (2007) Angew. Chem. Int. Ed., 46, 6495-8.

131 Dichiarante, V. and Fagnoni, M. (2008) Synlett, 787-800. 
